\title{
IMPACTS OF RAINFALL AND VULNERABILITIES IN THE METROPOLITAN REGION OF BAIXADA SANTISTA, BRAZIL
}

\author{
${ }^{1}$ FABIANO DE ARAUJO MOREIRA, ${ }^{2}$ NÚRIA APARECIDA MIATTO RAMPAZO \& \\ ${ }^{3}$ MARINA SÓRIA CASTELLANO \\ ${ }^{1}$ Department of Geography, University of Campinas, Brazil. \\ ${ }^{2}$ Department of Energy/Faculty of Mechanical Engineering, University of Campinas, Brazil. \\ ${ }^{3}$ Center for Human Sciences, State University of Western Paraná, Brazil.
}

\begin{abstract}
In altered environments, natural events such as rainfalls can bring a series of damages and their impacts are related not only to rainfall itself, but also to the socioeconomic aspects of the population. This paper aims to discuss the process of urbanization and occupation of the municipalities of the Metropolitan Region of Baixada Santista/RMBS (Brazil) and the vulnerability of the population considering the events triggered by rainfall in the decade of 2000. For this purpose, the events were collected in pre-existing electronic journals and official databases. The impacts were mapped based on the Social Vulnerability Index, provided by the Brazilian Federal Government's Planning, Development and Management Ministry. A total of 33 types of impacts related to rainfall across the RMBS were identified, with nearly 42,000 occurrences for the period. The event triggered by heavy rains with the highest number of deaths occurred in the municipality of Guarujá. During the whole period, the years of 2008 and 2009 stand out with the higher number of occurrences, mainly affecting the municipalities of Peruíbe and Mongaguá, which faced important rain episodes in the summers of both years. It was observed that there was no direct relationship between vulnerability and the number of occurrences related to rainfall, a tendency that differs from other similar studies, that emphasizes the most vulnerable population is the most affected by these types of events. This fact could be explained by the use of a municipal index, which have generalized specificities inside the urban area.
\end{abstract}

Keywords: Brazil, disasters, rainfall, urbanization, vulnerability.

\section{INTRODUCTION}

The Brazilian urbanization is associated with the generation of poverty since the accelerated and uncontrolled growth of the cities induces an urban crisis [1], as a large part of the population does not have access to essential services. The problem becomes even more serious with the fact that $83.8 \%$ of the country's population lives in urban centers.

One of the features of urbanization is the modification of the natural environment [2-7], which include the replacement of green areas, paving, densification of the population, waterproofing of soil, presence of pollutants, among others, which contribute to changes in the energy, thermal and water balances.

In these altered environments, natural phenomena such as rainfall can bring a series of problems. Their impacts may include direct effects, relating to the most visible consequences, such as the destruction of buildings and deaths; and indirect effects, which arise later and are more difficult to attribute to events, such as influence on the economy and social life [8].

The impacts associated with rainfall are not only related to precipitation itself, but also to the socioeconomic aspects of the population involved $[9,10]$. In this way, the agent of the disaster cannot be considered independent of the social context in which it occurs: it must include characteristics of land occupation, planning and the dynamics of the affected society. 
This paper aims to discuss the process of urbanization and occupation of the municipalities of the Metropolitan Region of Baixada Santista/RMBS (Brazil) and the vulnerability of the population considering the events triggered by rainfall in the decade of 2000 .

\section{STUDY AREA}

The RMBS is located on the coast of the state of São Paulo, Brazil (Fig. 1) and occupies an area of $2.818 \mathrm{~km}^{2}$, englobing nine municipalities: Bertioga, Cubatão, Guarujá, Itanhaém, Mongaguá, Peruíbe, Praia Grande, Santos and São Vicente, totaling more than 1.6 million inhabitants, which corresponds to almost $4.0 \%$ of the total population of the state of São Paulo, the most economically important state in the country. Due to tourism, the area coexists with an expressive floating population, which can more than double in the high seasons. Although $67 \%$ of the region is vegetated, it presents a high degree of urbanization (over 97\%) and population density.

In this region, confined between the coast and the Serra do Mar massif, there are mangrove areas, representing about $8.0 \%$ of the surface of the region, with the main local mangrove systems being those of the Estuarine Complex of Santos/São Vicente, on the Atapanhaú River, on the Bertioga Canal and at the mouth of the Itanhaém River. In addition, we can highlight the presence of the Atlantic Forest, representing about $40.0 \%$ of its surface, as well as $10.0 \%$ of the restinga system.

High rainfall volumes throughout the year and the fact that there is no significant difference in the distribution of precipitation between seasons shows the precipitation mechanisms on the coast are distinct from those in more continental areas [11]. This sector constantly registers frontal systems, sea breezes and the action of the South Atlantic Convergence Zone, mainly in
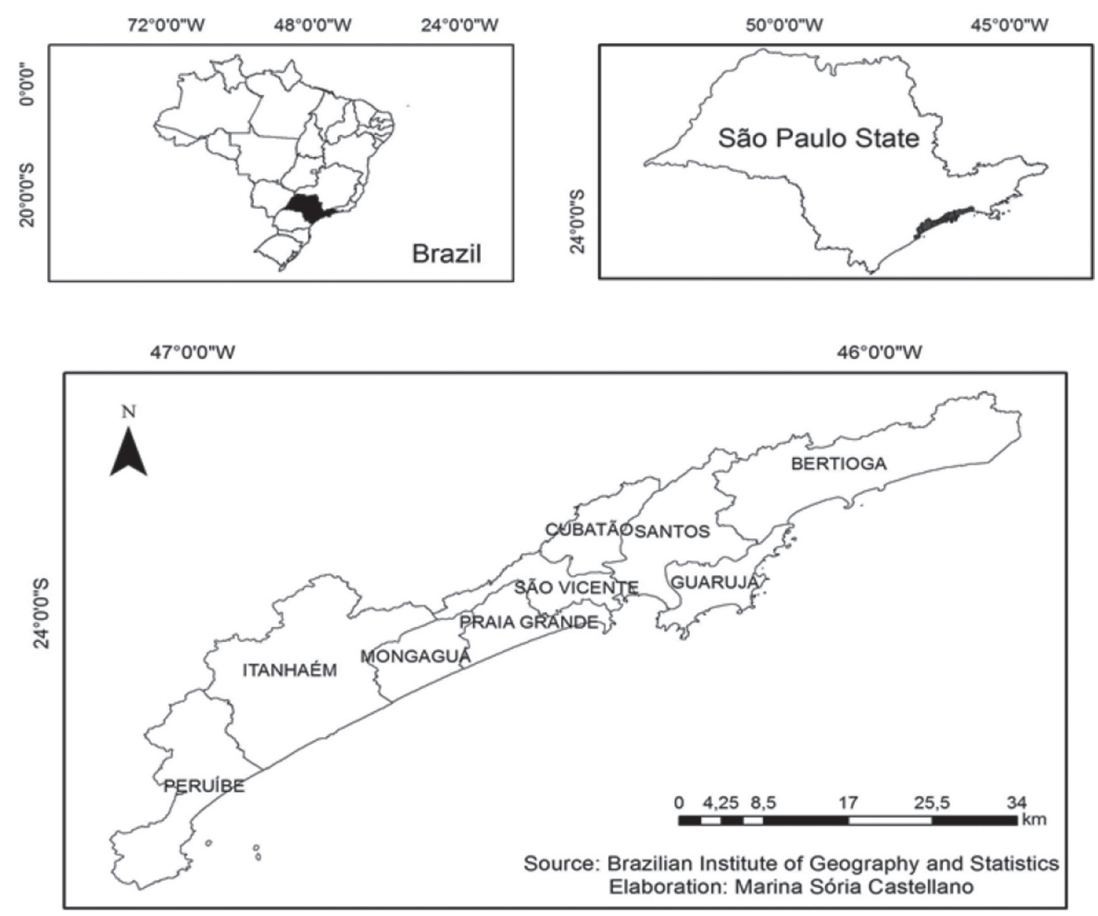

Figure 1: Location of the Metropolitan Region of Baixada Santista in Brazil. 
the summer, as well as local precipitation intensified in some points by the orographic effect. The temperatures are constantly high, and all these factors causes a naturally fragile and unstable environment, promoting strong chemical weathering.

The singularities of the area in relation to its physical characteristics were determinant in the process of local urbanization and economic development, as well as in the emergence of susceptible areas and vulnerable populations. Being one of the oldest occupying areas of the country, its environment has been altered for several centuries, significantly impacting its original natural characteristics.

Its regional importance is evident with the presence of the largest port, petrochemical and steel pole in Latin America [12], with the port representing 25.1\% of the total Brazilian trade balance in 2010 [13]. The area has vocations that are apparently disparate because of its economic potential (large port and industrial pole and tourism potential), which combine with conservation reserves and areas of legal protection, denoting extreme complexity in its spatial relationships [12].

The intense urbanization has significantly altered the physical environment, and the conservation of the natural areas close to the urbanized areas continues to be considered of little importance by the government. Young [14] emphasizes that the lack of conservation of natural areas in the RMBS is observed from the processes of environmental degradation and impacts related to urban activities.

Numerous anthropogenic actions contribute to the increase of environmental problems in the region: mangroves and estuarine waters are contaminated by the heavy industry effluents located in Cubatão, while toxic gases released by the industries promote erosive processes on the hillsides indirectly, by contributing for the loss of vegetation; continuous deforestation for the expansion of the urban area; the characteristics of the areas near the sea have been almost completely modified, losing the original areas of dunes and flooded valleys; contamination of soil and water by effluents and municipal solid waste; irregular occupations that impact the local characteristics of the soil or that increase the vulnerability of the population in relation to phenomena such as floods or landslides, among others [14].

The vulnerability of the population, in addition to the problems arising from the impact of human action on the environment, is also identified by activities that should be guaranteed by local governments, such as basic sanitation, garbage collection and sewerage, access to services such as health and public transportation, as well as problems related to the security sector. All these issues have arisen or were intensified due to the spatial segregation caused by the occupation of the city of Santos by the population with high or medium purchasing power, especially in the coast area with great verticalization which, through real estate speculation, expelled the less affluent population to distant and irregular regions, highlighting the municipalities neighboring Santos that lack more incisive policies on urban occupation.

Such facts illustrate contemporary, generalized aspects that characterize urban coastal occupation: the lack of planning and the difficulty of public policies to operate in an effective way and at the same speed as urban occupation. This makes the challenges for the planning of social and environmental public policies significant in RMBS.

\section{METHODOLOGY}

The main source of occurrences associated with rain episodes in the RMBS were the news published in electronic journals available on the internet and pre-existing databases, with information from Brazilian institutions such as the Institute for Technological Research (IPT), the Civil Defense (Disaster Records Database) [15] and Natural Disaster Database of the Institute for Meteorological Research (IPMet) [16]. 
The database was systematized in Microsoft Excel, organizing the information in the following columns: date, time, location, phenomenon, characteristic of the phenomenon (eg. rain duration), impacts and source. In turn, the impacts were subdivided into: environmental, material and/or economic damages; number of fatalities, homeless, displaced, missing and/or buried, sick or injured, and affected persons. It should be noted that the category 'environmental, material and/or economic damage' has been filled with a variety of related damages, from flooding to roadblocks or cracking of buildings, among others.

The mapping of the occurrences was made to understand where the problems associated with rains occurred more frequently and which were the most affected social strata. It should be noted that although the use of indexes offers limitations to the research, precisely because they do not represent the reality, they bring information that can characterize certain areas and communities, being a valuable instrument of analysis and comparison between different areas.

It is important to emphasize that the concept of vulnerability is quite complex and may be associated with many social factors. According to Cutter et al. [17], within the social sciences, there is a consensus that some key factors influence the vulnerability of a given group, including lack of access to resources, limited political representation, insufficient social capital, among others. Thus, the differences between the concepts of vulnerability in different academic researches are due to the selection of the variables and the weights given to each of them, generating several indexes associated to the theme, such as the Social Vulnerability Index (SoVI), developed by Cutter et al. [17], considered the academic standard for measuring social vulnerability.

In this work, it was used the Atlas of Social Vulnerability of the Institute of Applied Economic Research (IPEA), an important and respected public foundation, linked to the Ministry of Planning, Development and Management of the Brazilian federal government. The Atlas of Social Vulnerability is a platform for consulting the Social Vulnerability Index (IVS), composed of 16 indicators and calculated from the arithmetic mean of three sub-indices. According to the Atlas, "These dimensions correspond to sets of assets, resources or structures, whose access, absence or insufficiency indicate if the life standard of families is low, suggesting, in the limit, the non-access and non-observance of the social rights" (free translation from Portuguese) [18].

The indices are detailed as follows:

- IVS Urban Infrastructure, which addresses the conditions of access to basic sanitation and urban mobility, factors that significantly impact the well-being of the population.

- IVS Human Capital, which involves health and education issues, aspects that determine directly the current and future perspectives of social inclusion.

- IVS Income and Labor, which group's income and other indicators that may create a situation of income insecurity.

All indicators were calculated from the 2000 and 2010 Demographic Census of the Brazilian Institute of Geography and Statistics (IBGE) and normalized on a scale of zero to one, where zero corresponds to the ideal situation (less vulnerability) and one to the worse situation (greater vulnerability) (Fig. 2).

Areas with an IVS value between 0 and 0.200 are classified as areas of very low vulnerability; between 0.201 and 0.300 , low vulnerability; between 0.301 to 0.400 , medium vulnerability; between 0.401 and 0.500 , high vulnerability and finally from 0.501 to one, very high vulnerability. 


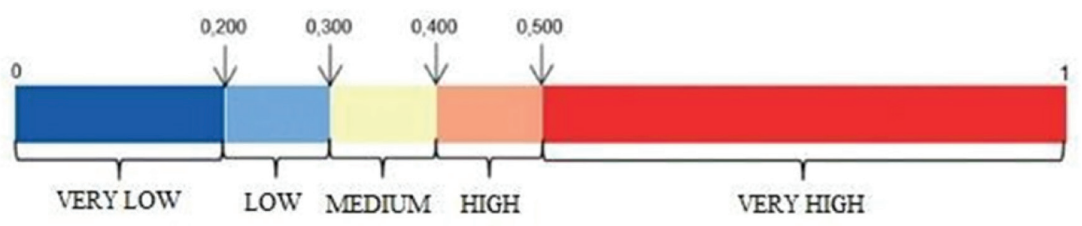

Figure 2: Vulnerability and classification values according to the Social Vulnerability Index (IVS) [18].

Only a few types of impacts were mapped, including: affected people, house collapse, fatal victims and total occurrences. The choice was made because the first two had the highest number of occurrences, the fatal victims were the most violent, and the total in order to give an overview of the RMBS situation.

\section{RESULTS}

A total of 33 types of rainfall impacts were identified throughout the RMBS, and they are listed in Table 1 according to the number of occurrences for each of them.

There were almost 42,000 occurrences, most notably the affected people, with more than half of the total recorded. However, it should be noted that the number of people affected by the events is certainly underestimated, since not all the news consulted provided this type of information, besides being impossible to know for sure the number of people who, in one way or another, were affected by the phenomenon. Moreover, there was no standard in the sources consulted: some considered the sum of the dead, wounded, homeless and displaced, while others included people without electricity, for example. Although it fades from the scope of this work, this fact illustrates the difficulty of providing a reliable picture of the real consequences of rainfall in the area.

Human losses and impacts may also be underestimated, because in some cases, the news only mentioned the event left people displaced or homeless - or even fatal victims - but did not specify that number.

In the analyzed period, 20 events with fatal victims were identified. Of the total (147 registered), 125 people lost their lives in a single event in the municipality of Guarujá, on April 4th, 2005, with landslides, vehicle damage and other impacts triggered by heavy rains. Four of the 20 events with fatal victims were caused by lightning, corresponding to $25.0 \%$ of the cases, totaling one victim in Cubatão, two in Itanhaém and one in São Vicente. All episodes of fatal victims caused by lightning occurred during the summer, the main season of lightning in Brazil, due to the warming caused by the Sun [19].

Regarding the temporal analysis, Figure 3 shows the total number of occurrences per year, for the entire RMBS. It is clear that the years 2008 and 2009 stood out, but mostly 2008, with a large number of cases. Among these, about $93.0 \%$ occurred only in the municipality of Peruíbe.

Figures 4-7 show the number of affected people, house collapses, fatal victims and total number of occurrences, respectively, by municipality, as well as their vulnerability ranges.

Even though the 'affected people' was the most numerous impact, it was concentrated in only two municipalities: Peruíbe and Itanhaém. Peruíbe stood out for the large number of cases, reaching just over 27,730 , with $71.0 \%$ of these occurring in just one day, January 12 th, 2008. The data provided by the Department of Water and Electric Energy [20] show a series 
Table 1: Impacts related to rainfall in RMBS and their respective number of occurrences.

\begin{tabular}{|c|c|}
\hline Type of impacts & Number of occurrences \\
\hline Affected people & 25.777 \\
\hline House collapse & 7.575 \\
\hline Displaced people & 4.150 \\
\hline Homeless people & 2.830 \\
\hline Sick and injured & 484 \\
\hline Falling trees & 227 \\
\hline Fatal victims & 147 \\
\hline Landslides & 118 \\
\hline Damage to paving & 104 \\
\hline Unroofing & 102 \\
\hline Surface flood & 69 \\
\hline Gradual floods & 24 \\
\hline Overflow of rivers and streams & 23 \\
\hline Interdicted properties & 22 \\
\hline Traffic/Interdiction of routes & 18 \\
\hline Interruption in transportation & 16 \\
\hline Vehicle damage & 14 \\
\hline Wall fall & 14 \\
\hline Cutting off power and water supply & 10 \\
\hline Block fall & 9 \\
\hline Accidents & 7 \\
\hline Coastal flood & 7 \\
\hline Barrier fall & 6 \\
\hline Traffic sign fall & 5 \\
\hline Erosion/hole & 4 \\
\hline Flooded houses & 4 \\
\hline Sudden floods & 4 \\
\hline Missing and/or buried persons & 4 \\
\hline Light pole fall & 4 \\
\hline Damage to bridges & 2 \\
\hline River flood & 2 \\
\hline Dam rupture & 1 \\
\hline Total & 41.783 \\
\hline
\end{tabular}

of inconsistencies, not accusing a heavy rain on this day. However, data from the nearby municipality of Mongaguá, which also had some impacts in this episode, indicate a rainfall of $248.5 \mathrm{~mm}$ between January 11th and 12th, 2008, and of $23.2 \mathrm{~mm}$ between January 12th and 13th, 2008 [20]. The analysis of vulnerability did not show the expected trend - that the most vulnerable populations would present greater exposure to risk and, consequently, more occurrences - since both municipalities mentioned are characterized as areas of low vulnerability in the regional scenario. 


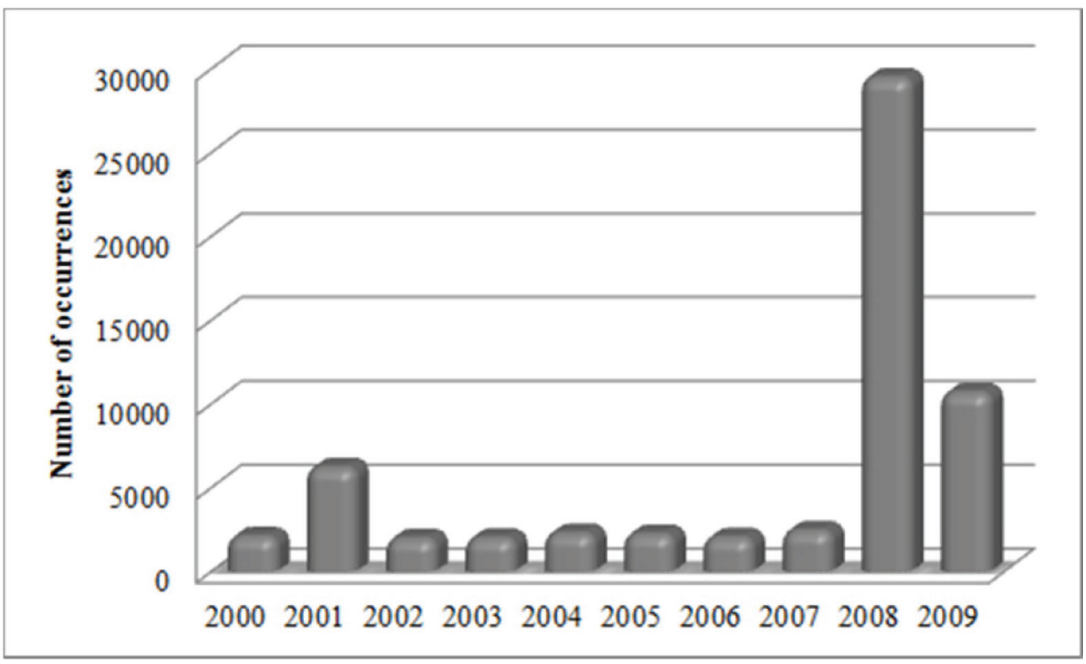

Figure 3: Total occurrences for all RMBS municipalities per year.

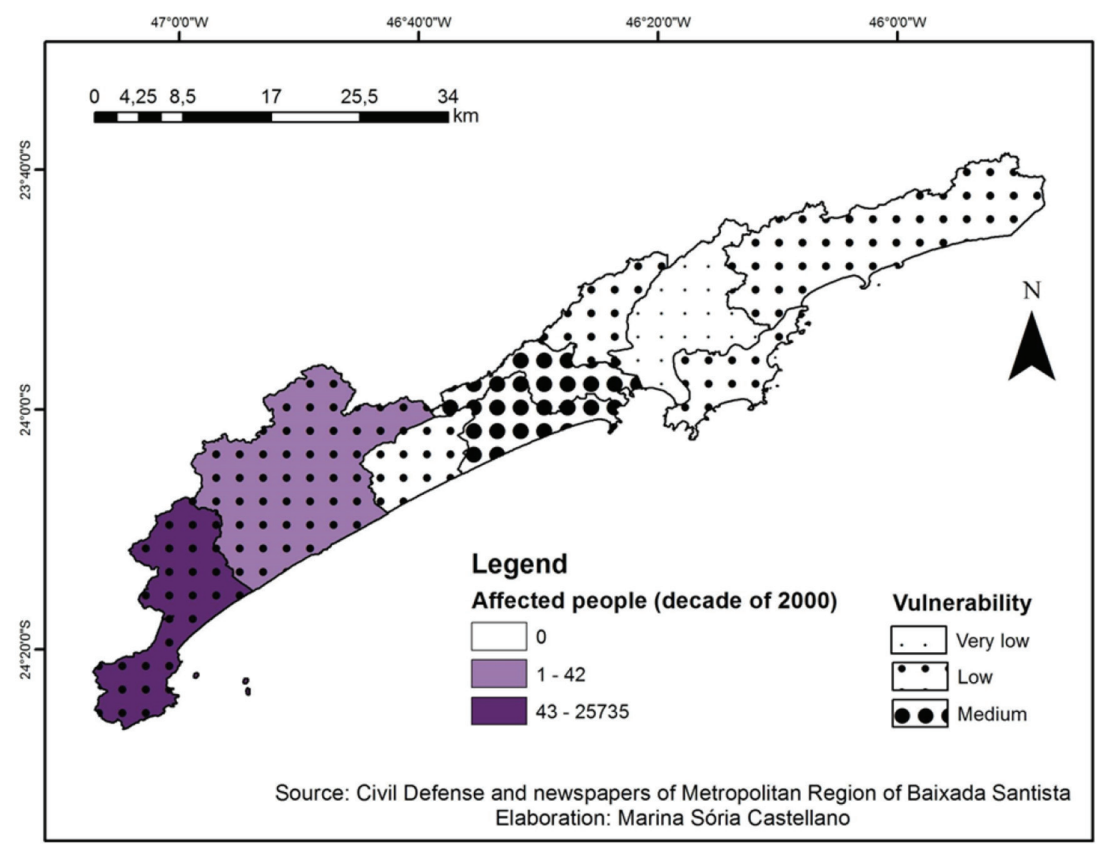

Figure 4: Affected persons and population vulnerability by municipality.

All municipalities of the RMBS presented house collapse, Peruíbe being the one with the highest number of occurrences, despite having presented low vulnerability in the period. As in the cases of affected people, a large part of the occurrences in this municipality (about $74.0 \%$ ) occurred on January 12th, 2008. It was noted that among the municipalities with medium vulnerability, São Vicente stood out with 69 cases and Santos, the only one with very low vulnerability, had 24 cases. 


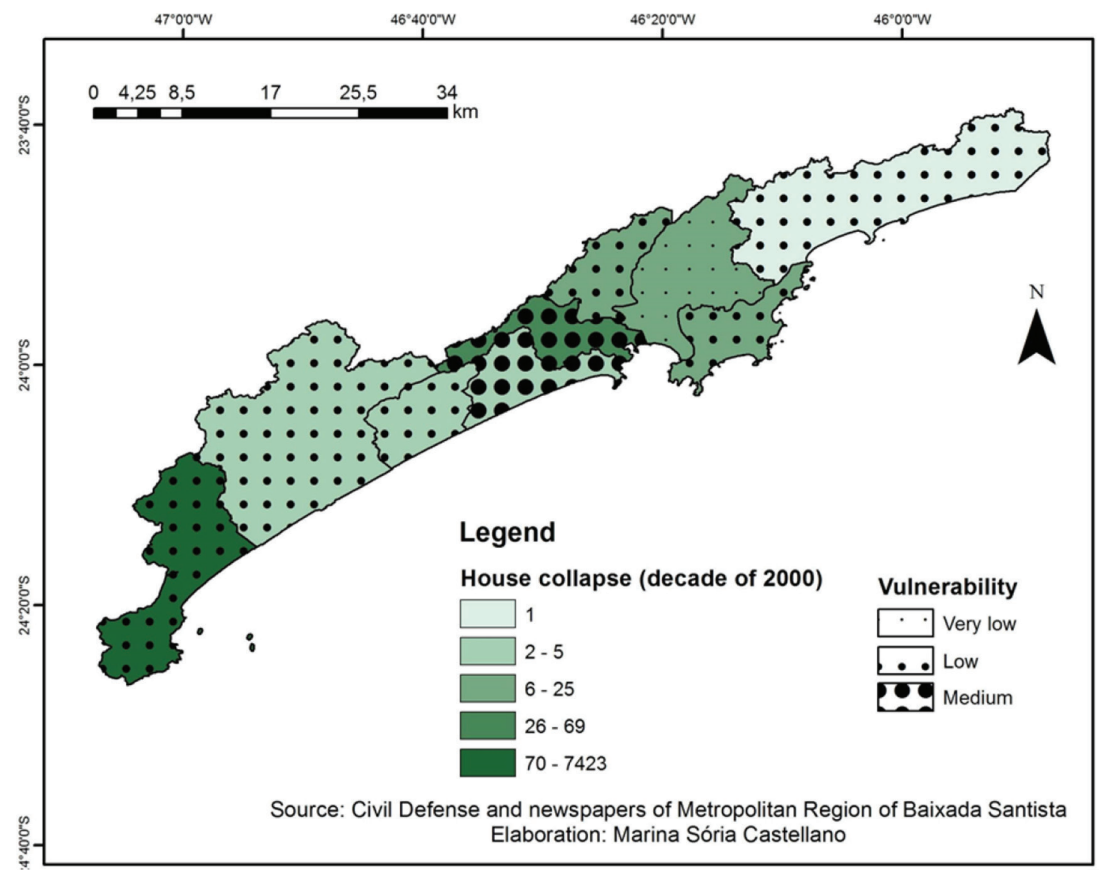

Figure 5: House collapses and vulnerability by municipality.

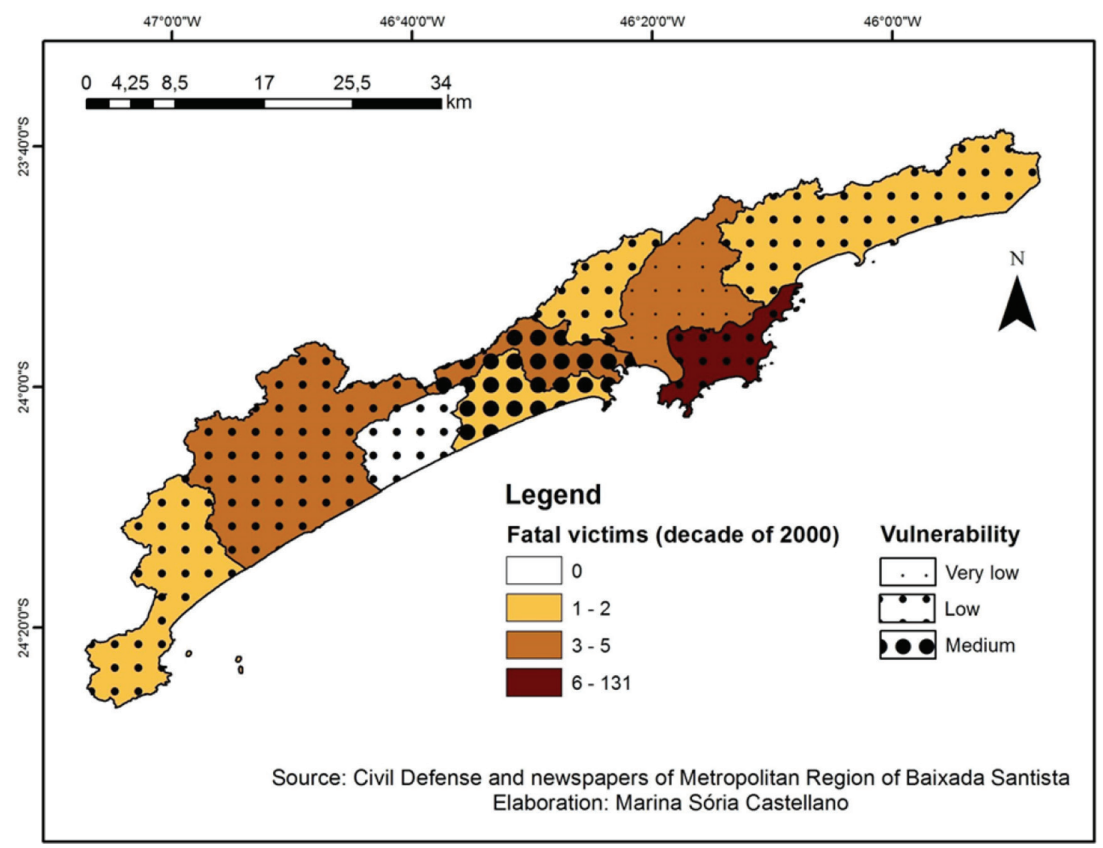

Figure 6: Fatal victims and population vulnerability by municipality. 


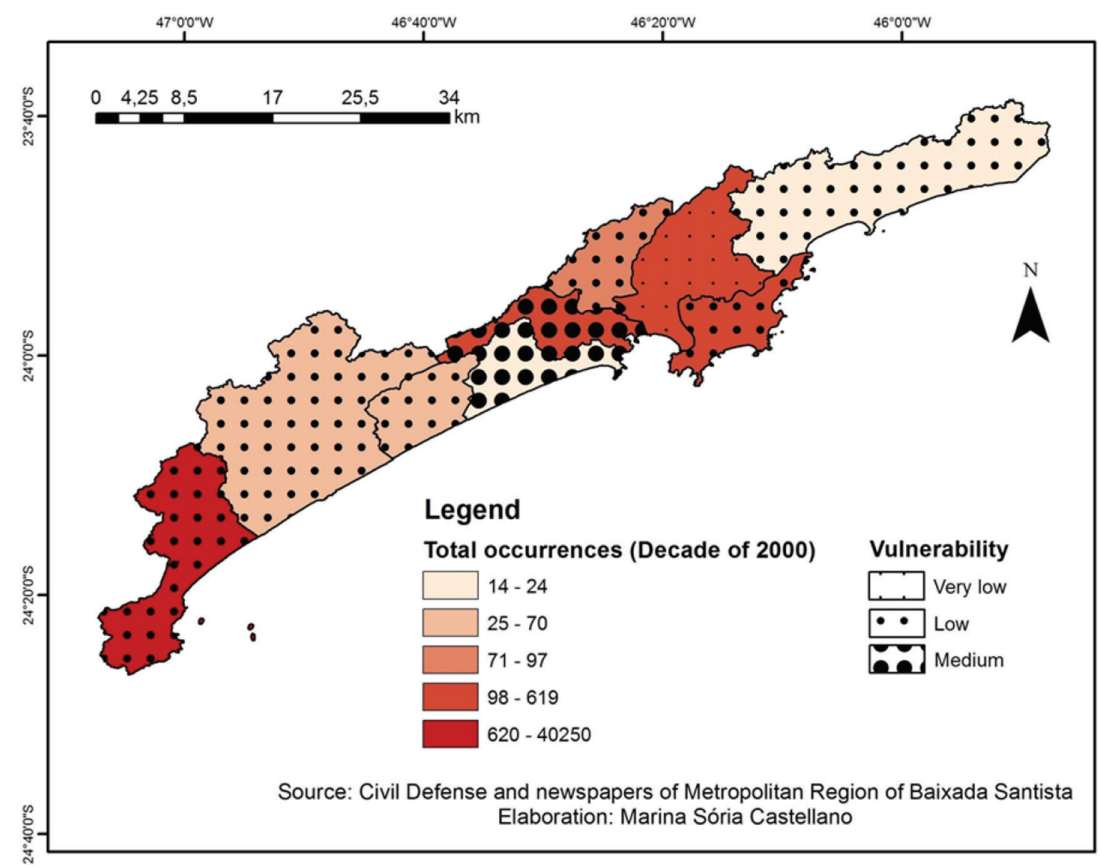

Figure 7: Total occurrences and vulnerability of the population by municipality.

With the exception of Mongaguá, all municipalities had cases of fatal victims. Santos, the only one with very low vulnerability, had three cases. Among the municipalities with low vulnerability, Guarujá stood out with 131 occurrences, 125 of which occurred in one day (April 4th, 2005). Among those with average vulnerability, São Vicente stood out with five cases.

Despite being classified as low vulnerability, Peruíbe was the municipality with the most occurrences: 40,250, especially in cases of house collapse, affected people, displaced people and homeless people. Most of the incidents were concentrated in 3 days: January 12th, 2001; January 12th, 2008; and February 25th, 2009 (all during the summer). Santos, the only one with very low vulnerability, presented an intermediate number of occurrences if compared to other municipalities (with emphasis on cases of tree falls and homeless people - not mapped in this work). Among those with low vulnerability, in addition to Peruíbe, it was noted that Guarujá presented a considerable number of cases (many records of homelessness and house collapse), and among those with a medium vulnerability population, São Vicente stood out (especially because of the many cases of house collapse and displaced people).

\section{CONCLUSIONS}

Some aspects should be taken into account from the spatialization and analysis of the data. At first glance, vulnerability classifications may seem strange, since there are no municipalities with high or very high vulnerability and most of them are classified as areas of low vulnerability. This was due to the fact that the index used in this study (IVS) was defined by the IPEA for several Brazilian municipalities - very heterogeneous areas - and not only for RMBS.

Another important point was that although the literature and knowledge of the area show that vulnerable populations tend to suffer more from rainfall, the mapping showed that there 
was no direct relationship between vulnerability and the number of cases related to rainfall, since municipalities with population in situation of greater vulnerability were not necessarily those with more occurrences and vice versa.

A clear example is Santos, the only one with very low vulnerability, but who presented many cases (including, in particular, the number of fatal victims). Peruíbe can also be cited, since it had the highest number of occurrences in the period, although it was classified as an area of low vulnerability.

Such trends can be explained by the use of the IVS, a municipal index, which probably generalizes and does not expose the specifics that smaller areas have within the municipalities, such as the neighborhoods. It is known, for example, that in Santos, neighborhoods such as São Bento, Nova Cintra, Marapé, Embaré and the Northwest Zone of the municipality have, historically, problems related to rainfall and are areas where extremely vulnerable populations inhabit.

Thus, it was noted that, for the purposes of this work, the municipal index did not accomplished the desired role, concealing essential particularities to understand how populations are exposed to risks associated with rainfall. This should be taken into consideration when using these data to formulate public policies aimed at reducing the vulnerability of populations at risk, and it is necessary to aggregate information available to other organizations or entities that have specific data of smaller areas within each municipality, such as some prefectures or civil defenses, for example.

\section{ACKNOWLEDGEMENTS}

This research was supported by Fundação de Amparo à Pesquisa do Estado de São Paulo (FAPESP - São Paulo State Research Support Foundation - Process no. 2013/24236-3 and 2014/14598-8), in connection with project "METROPOLE: An Integrated Framework to Analyse Local Decision Making and Adaptive Capacity to Large-Scale Environmental Change: Community Case Studies in Brazil, UK and the US" (Forum Belmont, Process no. G8MUREFU3 2201-040, Fapesp Process no. 2012/51876-0).

\section{REFERENCES}

[1] Santos, M., A urbanização brasileira, São Paulo: HUCITEC, 1993.

[2] Sant'Anna Neto, J.L., Clima e organização do Espaço, Boletim de Geografia. Universidade Estadual de Maringá, ano 16, no. 1, 1998.

[3] Brandão, A.M.de P.M., Clima urbano e enchentes na cidade do Rio de Janeiro. In: Guerra, A.J.T. \& Cunha, S.B.da (eds), Impactos ambientais urbanos no Brasil, Rio de Janeiro: Bertrand Brasil, 2001.

[4] Yahn, A.G. \& Giacomini, A.A.R.V., Recursos hídricos e saneamento. In: Fonseca, R.B., Davanzo, A.M.Q. \& Negreiros, R.M.C. (eds), Livro verde: desafios para a gestão da Região Metropolitana de Campinas, Campinas: Unicamp/IE, 2002.

[5] Gonçalves, N.M.S., Impactos pluviais e desorganização do espaço urbano em Salvador. In: Monteiro, C.A.de F. \& Mendonça, F., Clima urbano, São Paulo: Contexto, 2003.

[6] Tucci, C.E. \& Braga, B. (eds), Clima e recursos hídricos no Brasil, Porto Alegre: ABRH, 2003.

[7] Nunes, L.H., Landslides in São Paulo, Brasil: an integrated historical perspective. Pages News, 19(2), 2011.

[8] Smith, K., Environmental hazards - assessing risk and reducing disaster, Londres: Routledge, 2004. 
[9] Mattedi, M.A., As enchentes como tragédias anunciadas: impactos da problemática ambiental nas situações de emergência em Santa Catarina, $\mathrm{PhD}$ thesis - Universidade Estadual de Campinas, 1999. (in Portuguese).

[10] Nunes, L.H., Mudanças climáticas, extremos atmosféricos e padrões de risco a desastres hidrometeorológicos. In: Hogan, D.J. \& Marandola Jr., E. (eds), População e mudança climática. Dimensões humanas das mudanças ambientais globais, Campinas: Núcleo de estudos de População - NEPO, Unicamp; Brasília: UNFPA, 2009.

[11] Nunes, L.H., Distribuição espaço-temporal da pluviosidade no Estado de São Paulo: tendências, variabilidade, processos intervenientes, EPUSP, 1997.

[12] Zundt, C., Baixada Santista: uso, expansão e ocupação do solo, estruturação de rede urbana regional e metropolização. In: Cunha, J.M.P.da, Novas Metrópoles Paulistas: População, vulnerabilidade e segregação, Campinas: Núcleo de Estudos de População - Nepo. Unicamp, 2006.

[13] CODESP - Controle de segurança dos portos, available at: http://www.codesp.com.br/

[14] Young, A.F., Mudanças climáticas: entre a coesão e a fragmentação dos assentamentos humanos, os conflitos e as transformações da paisagem na Baixada Santista. In: Hogan, D.J. \& Marandola JR., E. (eds), População e mudança climática: dimensões humanas das mudanças ambientais globais, Campinas: Núcleo de Estudos de População - Nepo. Unicamp; Brasília: UNFPA, 2009.

[15] Sistema Integrado de Informações sobre Desastres (S2ID). Available at: http://150.162.127.14:8080/bdrd/bdrd.html. (accessed July 2014).

[16] IPMET - Instituto de Pesquisas Meteorológicas. Available at: http://www.ipmet.unesp. br/index2.php?menu_esq1=\&abre=ipmet_html/defesa_civil/index.php. (accessed 24 January, 2015).

[17] Cutter, S.L., Boruff, B.J. \& Shirley, W.L., Social vulnerability to environmental hazards. Social Science Quarterly, 84, pp. 242-261, 2003. https://doi.org/10.1111/1540-6237.8402002

[18] IPEA - Instituto de Pesquisa Econômica Aplicada. Available at: http://ivs.ipea.gov.br/ ivs/

[19] Tavares, R., Clima, Tempo e Desastres. In: Tominaga, L.K., Santoro, J. \& Amaral, R. (eds), Desastres Naturais: conhecer para prevenir, $1^{\mathrm{a} e d}$. São Paulo: Instituto Geológico, 01, pp. 111-146, 2009.

[20] Departamento de Águas e Energia Elétrica. Available at: http://www.hidrologia.daee. sp.gov.br/. (accessed 20 March, 2017). 